\title{
The Systemic Zinc Homeostasis Was Modulated in Broilers Challenged by Salmonella
}

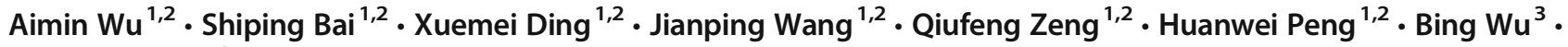 \\ Keying Zhang ${ }^{1,2,4}$
}

Received: 7 May 2019 / Accepted: 26 September 2019 / Published online: 22 October 2019

(C) The Author(s) 2019

\begin{abstract}
Salmonella challenge leads to systemic responses that induce the hypozincaemia in mice, which is considered a vital strategy against Salmonella invasion. However, it is not yet known if this phenomenon occurs in broilers. To investigate the change in zinc homeostasis of broilers against Salmonella challenge, 1-day-old male broilers were fed with the basal diet for 7 days. Afterwards, broilers were orally inoculated with either 0 or $0.5 \times 10^{8}$ CFU Salmonella Typhimurium (ST). The serum and selected tissues of Salmonella-challenged and non-challenged broilers were collected at 1, 3 and 7 days post-challenge for zinc homeostasis analysis. Our results showed that Salmonella challenge results in hypozincaemia (serum zinc decrease and liver zinc increase) via modulating the systemic zinc homeostasis of broilers. A profound, zinc transporter-mediated zinc absorption and redistribution affecting zinc homeostasis provided a mechanistic explanation for this phenomenon. In addition, we found that the zinc importers Zip5, Zip10, Zip11, Zip12, Zip13 and Zip14 were mainly downregulated in Salmonella-challenged broilers to reduce zinc absorption in the duodenum, while the Zip14 mRNA expression was upregulated to redistribute zinc into the liver. Collectively, these findings reveal that broilers counteract Salmonella infection via modulating their systemic zinc homeostasis.
\end{abstract}

Keywords Salmonella $\cdot$ Broiler $\cdot$ Zinc $\cdot$ Hypozincaemia $\cdot$ Zinc homeostasis

\section{Introduction}

Food-borne Salmonella remains a major public health concern worldwide, being responsible for hundreds of millions of cases of human gastroenteritis [1-3]. Broiler meat contaminated with Salmonella is the primary vehicles for human salmonellosis $[4,5]$. Aside from its impact on human health,

Electronic supplementary material The online version of this article (https://doi.org/10.1007/s12011-019-01921-1) contains supplementary material, which is available to authorized users.

Keying Zhang

zkeying@sicau.edu.cn

1 Institute of Animal Nutrition, Sichuan Agricultural University, Chengdu 611130 Sichuan China

2 Key Laboratory of Animal Disease-Resistance Nutrition, Ministry of Education, Chengdu 611130 Sichuan China

3 Sichuan Chelota Group, Liangshui Village, Jinyu Town Guanghan City 618300 Sichuan China

4 Animal Nutrition Institute, Key Laboratory of Animal Disease-Resistance Nutrition, Ministry of Education, Sichuan Agricultural University, Huimin Road 211 Chengdu 611130 China
Salmonella infection results in growth depression, intestinal inflammation, high mortality and cross-contamination in broilers $[1,6]$, which causes substantial economic loss to the poultry industry per year.

In mice, Salmonella infection induces hypoferraemia (serum iron decrease and liver iron increase), as iron plays a role in the regulation of the inflammatory response [7, 8]. Since other critical physiological functions also involve iron, all living organisms require iron to survive, including Salmonella [9]. The functions of hypoferraemia are considered to be the host defensive, because it decreases the availability of iron for Salmonella in a process termed "nutritional immunity" [10-13]. Besides iron, zinc also plays vital roles in host nutritional immunity [14, 15]. Similarly, hypozincaemia has also been observed after acute administration of numerous pathogens and agents, such as Mycobacterium tuberculosis, IL-6 and LPS [16-18]. This process is accompanied by a decrease in the serum zinc concentration and an increase in the zinc content in the liver due to the altered activity of zinc transporters, especially upregulation of Zip14 gene expression [16]. Meanwhile, there is an increased expression of zinc-binding protein metallothionein (MT) via a 
mechanism associated with oxidative stress $[16,19]$. Notably, enhancing MT expression availability controls the "free zinc" (labile zinc that is available for binding by newly synthesized zinc metalloproteins) concentration in cells, and limits Salmonella infection in macrophages [20]. Thus, hypozincaemia has been considered an effective strategy to limit pathogens from acquiring sufficient zinc for infection and proliferation in mice [16]. Interestingly, a similar phenotype was also observed in broilers under Escherichia coli or LPS stimulation [21]. In this context, broilers could also use hypozincaemia as a useful defence strategy against pathogen infection. However, this has not yet been studied in broilers under Salmonella infection, and the roles and mechanisms of hypozincaemia in broilers are also largely unknown.

Therefore, in this study, we investigated the impact of Salmonella challenge on the systemic zinc homeostasis of broilers and revealed how broilers modulate their zinc homeostasis to counteract Salmonella infection.

\section{Materials and Methods}

\section{Animals and Diets}

A total of 48, 1-day-old Arbor Acres (AA) male broilers were fed the basal diet for 7 days. Afterwards, the broilers were randomly divided into two treatment groups: nonchallenged control group; Salmonella-challenged group. The basal diet (Table 1) was formulated to meet the requirements recommended by the National Research Council. All broilers were placed in a single thermocontrolled room. Room temperature was maintained at $32{ }^{\circ} \mathrm{C}$ during the first 3 days of life and then decreased by 2 to $3{ }^{\circ} \mathrm{C}$ per week. Broilers were given ad libitum access to feed and water and 24-h illumination throughout the whole experimental trial. The experimental procedures used in this study were approved by the Animal Care Advisory Committee of Sichuan Agricultural University.

\section{Oral Salmonella Inoculation}

On day 7 , broilers were orally inoculated with either 0 or $0.5 \times 10^{8} \mathrm{CFU}$ Salmonella enterica serovar Typhimurium (ST), according to the previous assignment (non-challenged vs. challenged). The method is detailed elsewhere [22]. The strain of ST used in this experiment was from the American Type Culture Collection (ATCC, No. 14028).

\section{Growth Performance}

The body weight of broilers was recorded at 7, 8, 10 and 14 days of age. These values were used to calculate the average body weight gain, according to the body weight of each growth phase.

\section{Sample Collection and Procedures}

At 1, 3 and 7 days post-challenge (at 8, 10 and 14 days of age), blood samples were taken from eight randomly selected birds in each group, and centrifuged at $2500 \mathrm{~g} /$ $\min$ for $10 \mathrm{~min}$ at $4{ }^{\circ} \mathrm{C}$ and then serum layer stored at $-20{ }^{\circ} \mathrm{C}$ for serum zinc concentration analysis. Afterwards, the broilers were sacrificed by $\mathrm{CO}_{2}$ to collect the liver, spleen, thymus, bursa of Fabricius, duodenum, jejunum, ileum and cecum for the determination of zinc content and expression levels of zinc metabolism-related genes. Note that selected birds had fasted $12 \mathrm{~h}$ before sample collection.

\section{RT-PCR}

Total RNA was extracted from the liver and duodenum using RNAiso Plus reagent (TaKaRa), according to the manufacturer's protocol and transcribed into cDNA by using the Prime Script ${ }^{\mathrm{TM}}$ RT reagent kit (TaKaRa). Quantitative real-time PCR system was performed on a CFX96 PCR system (BioRad) with the oligonucleotide sequences shown in Table S1. Relative gene expression was calculated with the $2^{\Delta \Delta \mathrm{Ct}}$ method [23], normalizing the results to the house-keeping gene $\beta$-actin.

\section{Zinc Measured by Inductively Coupled Plasma Mass Spectroscopy}

An Agilent $7500 \mathrm{cx}$ inductively coupled plasma mass spectroscopy (ICP-MS) instrument (G3148B ISIS, Agilent Technologies, Japan) equipped with a G3160B I-AS integrated autosampler was employed to measure the ion profile since it allows a reduction in the detection time and volume of each sample compared with similar instruments. The typical operating conditions and the pretreatments of samples used in this study have been described previously [24].

\section{Statistical Analysis}

Statistical analysis was performed using GraphPad Prism software (Version 5.01). All results were presented as mean \pm SEM. Statistical tests included the unpaired two-tailed Student's $t$ test as appropriate with Bonferroni post hoc tests. Significance ( $P$ value) was evaluated at the 0.05 level. 
Table 1 Composition and nutrient concentrations of the diet (air dry-basis, \%)

\begin{tabular}{lrlr}
\hline Ingredients & Amount & Calculated nutrient concentrations & Amount \\
\hline Corn & 54.30 & Metabolisable energy (kcal/kg) & 2950.00 \\
Soybean meal & 38.12 & Crude protein & 21.00 \\
Soybean oil & 3.40 & Calcium & 1.01 \\
L-Lysine hydrochloride & 0.15 & Non-phytate phosphorus & 0.45 \\
DL-Methionine & 0.25 & Lysine & 1.15 \\
Calcium carbonate & 1.14 & Methionine & 0.50 \\
Dicalcium phosphate & 1.86 & Methionine and cystine & 0.86 \\
Sodium chloride & 0.40 & & \\
Choline chloride & 0.15 & & \\
Premix & a & 0.23 &
\end{tabular}

a Supplied the following per kilogram of complete feed: $\mathrm{Cu}\left(\mathrm{CuSO}_{4} \cdot 5 \mathrm{H}_{2} \mathrm{O}\right), 8 \mathrm{mg} ; \mathrm{Fe}\left(\mathrm{FeSO}_{4} \cdot 7 \mathrm{H}_{2} \mathrm{O}\right), 100 \mathrm{mg} ; \mathrm{Mn}$ $\left(\mathrm{MnSO}_{4} \cdot 7 \mathrm{H}_{2} \mathrm{O}\right), 120 \mathrm{mg} ; \mathrm{Zn}\left(\mathrm{ZnSO}_{4} \cdot 7 \mathrm{H}_{2} \mathrm{O}\right), 80 \mathrm{mg}$; $\mathrm{Se}\left(\mathrm{Na}_{2} \mathrm{SeO}_{3}\right), 0.3 \mathrm{mg}$; I (KI), $0.70 \mathrm{mg}$; vitamin A (retinyl palmitate), $8000 \mathrm{IU}$; cholecalciferol, $1000 \mathrm{IU}$; vitamin E (DL-tocopheryl acetate), $20 \mathrm{IU}$; thiamine, $0.8 \mathrm{mg}$; riboflavin, $2.5 \mathrm{mg}$; pyridoxine, $1.5 \mathrm{mg}$; pantothenic acid, $2.2 \mathrm{mg}$; folic acid, $0.55 \mathrm{mg}$; nicotinic acid, $35 \mathrm{mg}$; and biotin, $0.18 \mathrm{mg}$

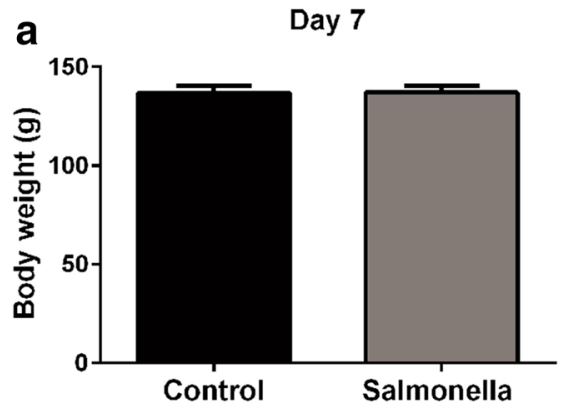

Day 10

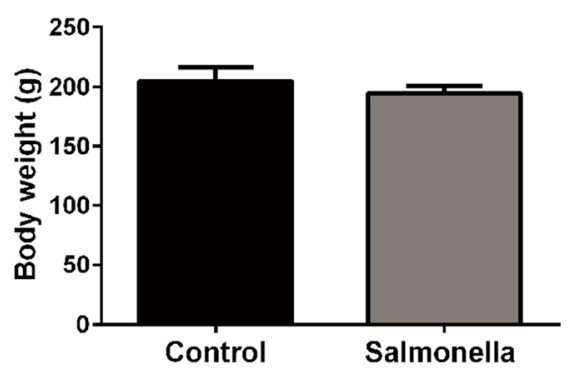

b $\quad 1 \mathrm{~d}$ post infection

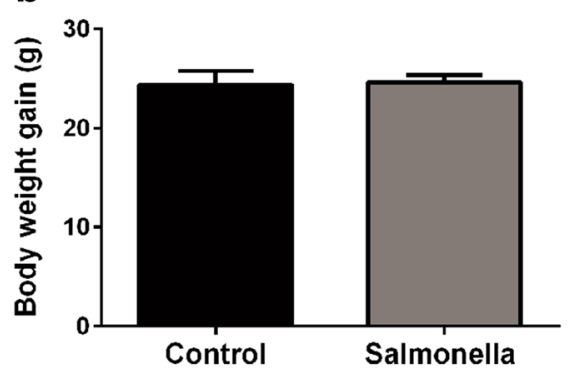

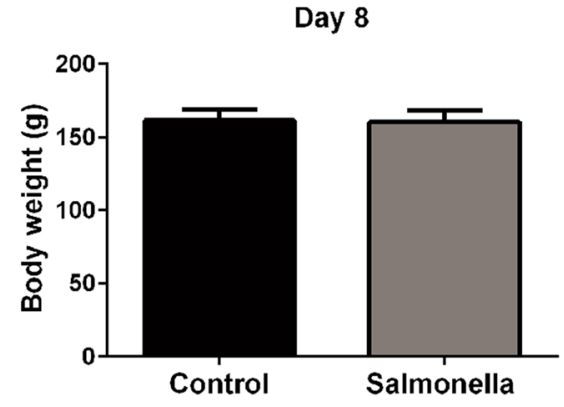

Day 14

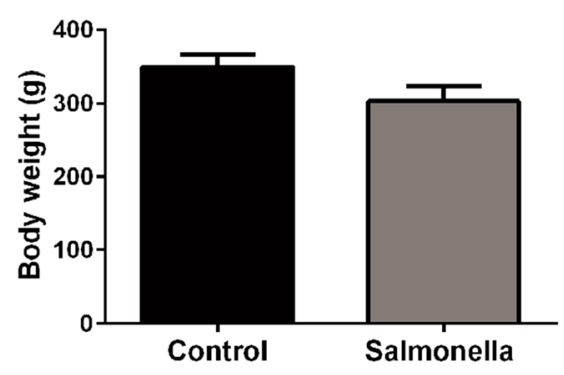

3 d post infection

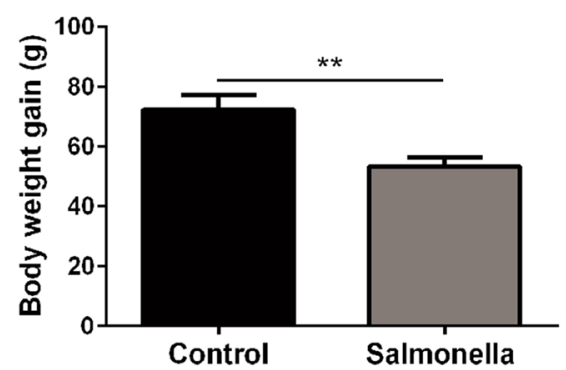

$7 \mathrm{~d}$ post infection

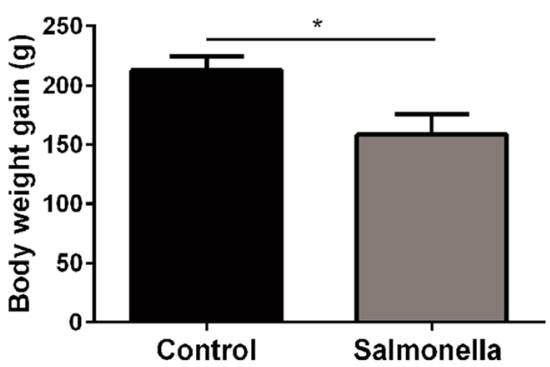

Fig. 1 The growth performance of 7 14 day-old broilers. a The average body weight of broilers at 7, 8, 10 and 14 days of age. $\mathbf{b}$ The average body weight gain of broilers at 1,3 and 7 days post-challenge $(n=8)$.

$* P<0.05, * * P<0.01, * * * P<0.001$, all data compare with control, the same with the follow figures 


\section{Results}

\section{Salmonella Challenge Decreased the Growth Performance of Broilers}

Our results showed that there was no significant difference in the average body weight between the control and Salmonella-challenged broilers (Fig. 1a), with only a slight tendency towards a decreased body weight of broilers at 14 days $(P=0.0953)$. In contrast, Salmonella challenge dramatically reduced the average body weight gain of broilers at 3 and 7 days post-challenge (Fig. 1b).

\section{Hypozincaemia Was Observed in Salmonella-Challenged Broilers}

Generally, mice challenged with Salmonella display profound changes in their metal metabolism [25]. In the case of zinc, "hypozincaemia" is among the changes observed in the period of acute inflammatory response. It is considered an effective strategy for mice to combat Salmonella challenge [16]. In broilers, hypozincaemia was also observed following Salmonella challenge (Fig. 2). Salmonella challenge resulted in a serum zinc decrease at 3 days post-challenge (Fig. 2a) and a liver zinc content increase, zinc was redistributed into the liver at 1 day post-challenge (Fig. 2b).

\section{Zinc Was Also Redistributed into the Bursa of Fabricius}

As noted above, zinc was redistributed into the liver in Salmonellachallenged broilers (Fig. 2), which is considered to be a response by the host defence system. A great deal of literature has already revealed that immune organs play crucial roles in the defence against Salmonella [22]. Whether the host will alter the zinc metabolism of their immune organs in response to Salmonella challenge remains unknown until now. We checked the zinc content in three different immune organs of broilers. As shown in Fig. 3, Salmonella challenge altered the zinc metabolism in the spleen and bursa of Fabricius. However, there was no difference in the content of zinc in the thymus (Fig. 3b). Intriguingly, Salmonella challenge slightly reduced the zinc content in the spleen (Fig. 3a), but significantly increased the zinc content in the bursa of Fabricius, suggesting that zinc was also redistributed into the bursa of Fabricius in Salmonella-challenged broilers.

\section{Salmonella Challenge Inhibited the Zinc Absorption in the Intestine}

As zinc is not stored in body, it must to be ingested daily and its homeostasis must to be accurately regulated. Whether the host mediates the hypozincaemia against Salmonella challenge through limiting the absorption of zinc was not fully known. Therefore, the duodenal, jejunal, ileal and cecal contents of zinc were measured by ICP-MS in this study. As shown in Fig. 4,
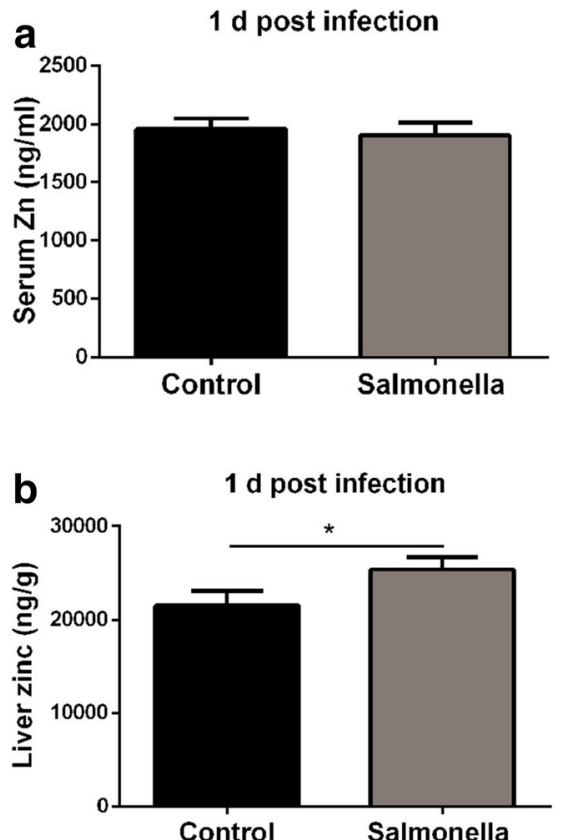
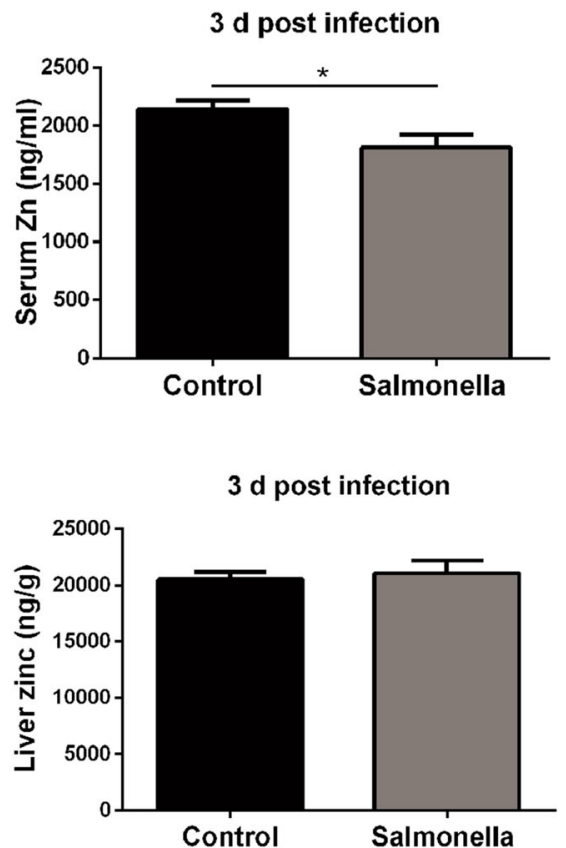
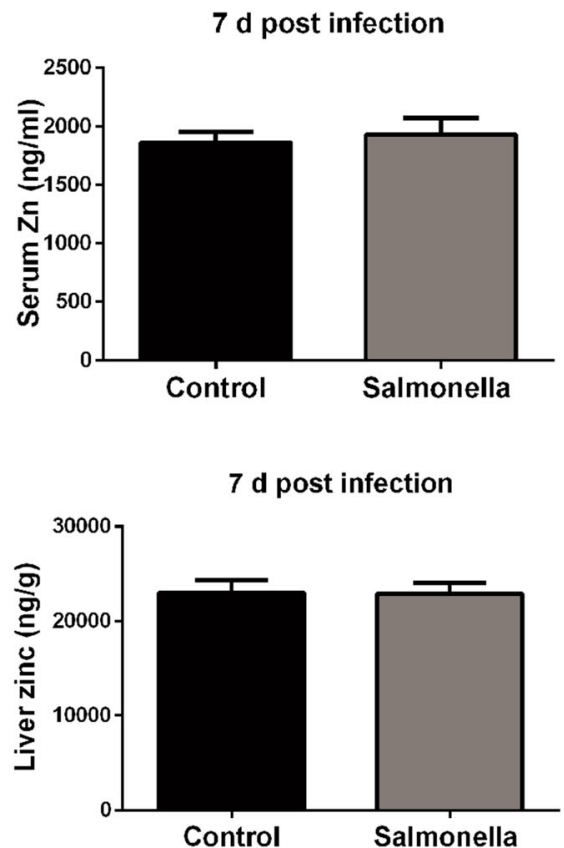

Fig. 2 Hypozincaemia was observed in Salmonella challenged broilers. The serum zinc concentration (a) and liver zinc content (b) of broilers at 1, 3 and 7 days post-challenge were detected by ICP-MS $(n=8)$ 
Salmonella challenge inhibited zinc absorption in the duodenum, and the zinc content of the duodenum in Salmonellachallenged broilers was less compared with the control group at the 1 day post-challenge (Fig. $4 \mathrm{a}$ ). Similar results were also observed in the ileum (Fig. 4c). Interestingly, Salmonella challenge resulted in zinc accumulation in the jejunum and cecum at 3 days post-challenge (Fig. $4 b, d$ ).

\section{Zinc Transporter-Mediated Hypozincaemia in Salmonella-Challenged Broilers}

Figures $2 \mathrm{~b}$ and $4 \mathrm{a}$ showed that Salmonella challenge altered the zinc homeostasis of the liver and duodenum, which plays a crucial role in regulating the systemic zinc homeostasis. The $M T$ mRNA expression was significantly upregulated in the liver at 1 day post-challenge (Fig. 5a). In addition, the host upregulated Zip14 (a zinc importer) mRNA expression to accumulate zinc in the liver (Fig. 5a). On the contrary, the mRNA expressions of zinc exporters ZnT1, ZnT4, ZnT5, ZnT6, ZnT8 and $Z n T 9$ in the liver were significantly downregulated in Salmonella-challenged broilers. Meanwhile, Salmonella challenge caused a significantly decrease in MT mTNA expression that was accompanied by differential expression of specific zinc transporters in the duodenum at 1 day post-challenge (Fig. 5b). The host limited the zinc absorption in the duodenum by downregulating the mRNA expression of zinc importers, such as Zip5, Zip9, Zip10, Zip11, Zip12, Zip13 and ZIP14, and decreasing the mRNA expression levels of the zinc exporters $Z n T 1$, ZnT4, ZnT6 and ZnT7 mRNA expression (Fig. 5b).

\section{Discussion}

Salmonella challenge results in diarrhoea and severely reduces the body weight of animals $[1,26]$. The impact of Salmonella challenge on the performance of broilers has been reported and
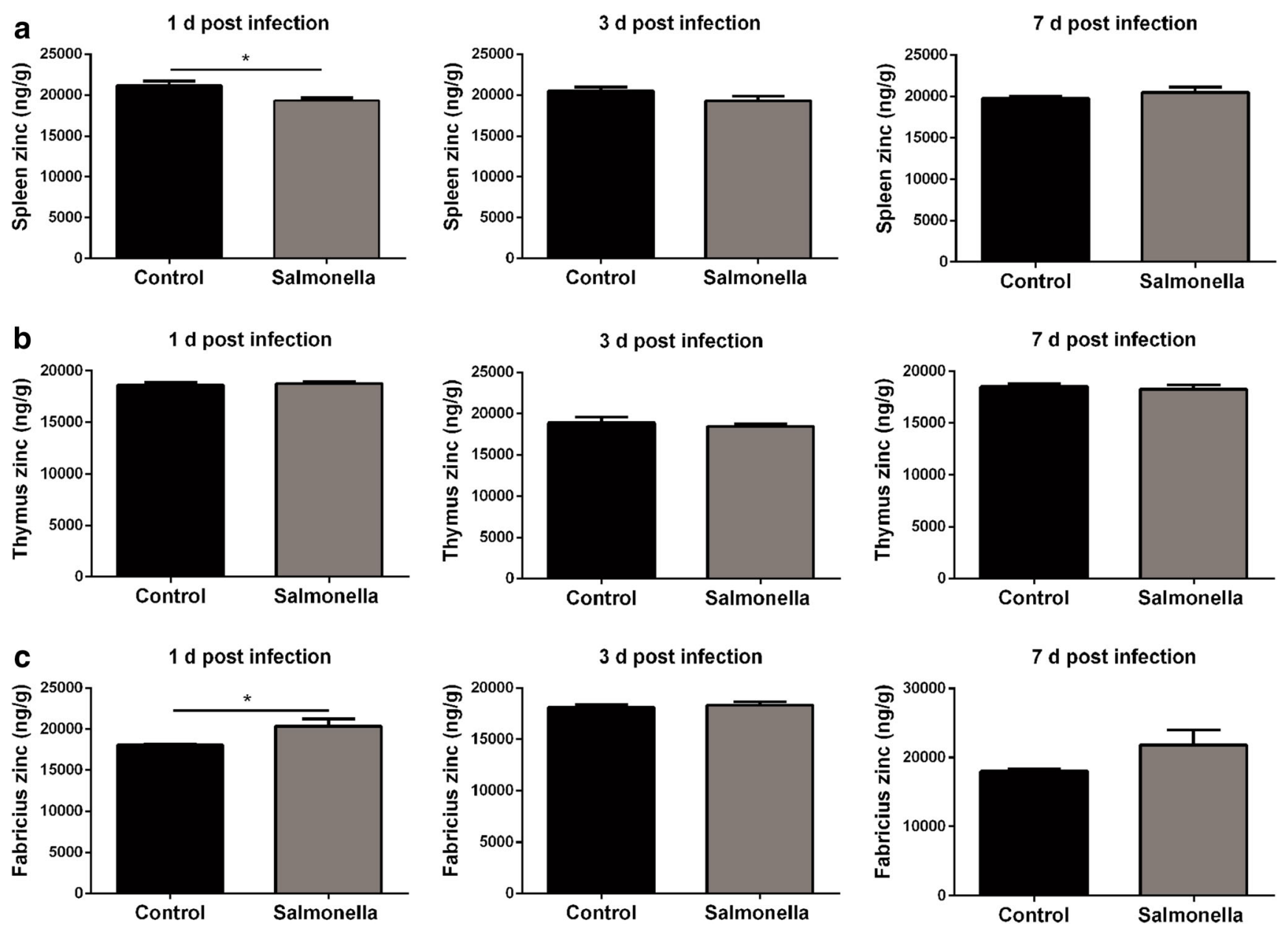

Fig. 3 Zinc was redistributed into the bursa of Fabricius. Zinc content in the spleen (a), thymus (b) and bursa of Fabricius (c) zinc content of broilers at 1 , 3 and 7 days post-challenge were detected by ICP-MS $(n=8)$ 

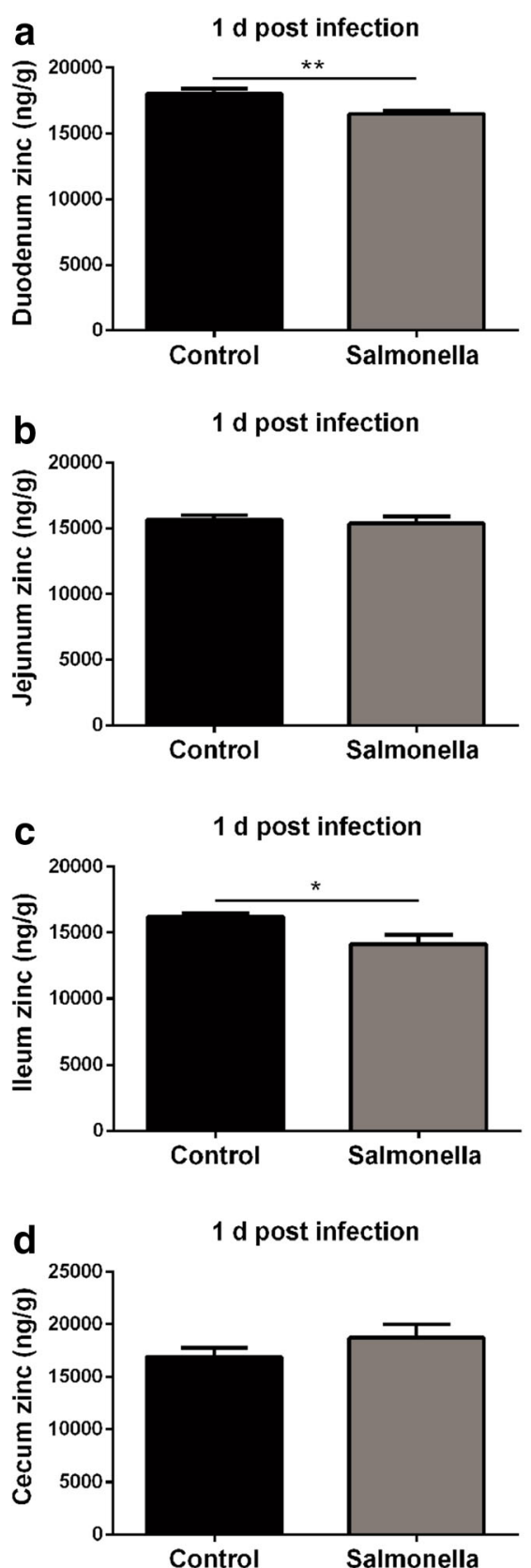

Fig. 4 Salmonella challenge inhibited the zinc absorption in the small intestine. Duodenal (a), jejunal (b), ileal (c) and cecal (d) zinc content of
$3 \mathrm{~d}$ post infection

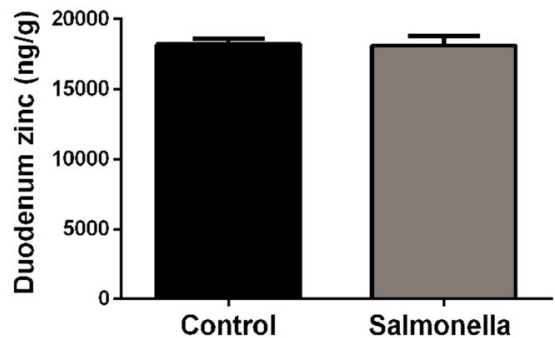

$3 \mathrm{~d}$ post infection

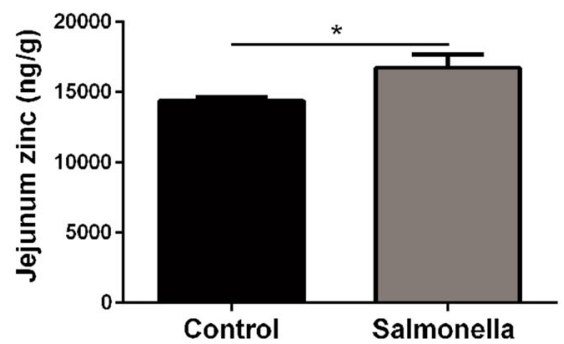

$3 \mathrm{~d}$ post infection

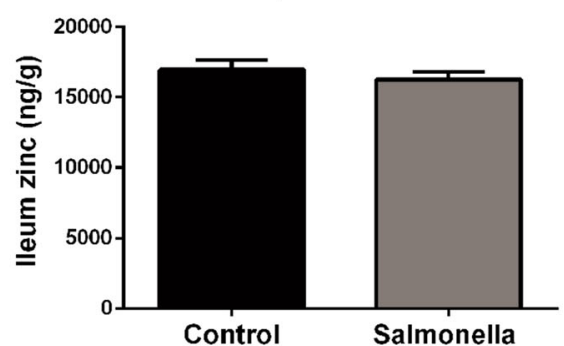

$3 \mathrm{~d}$ post infection

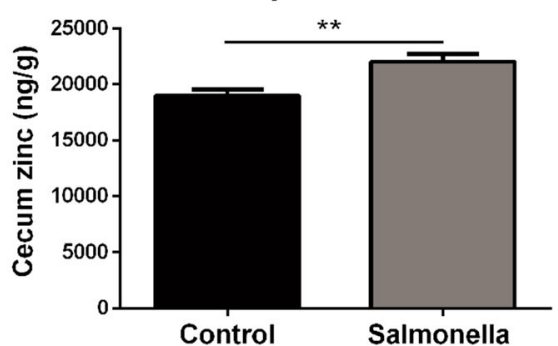

$7 \mathrm{~d}$ post infection

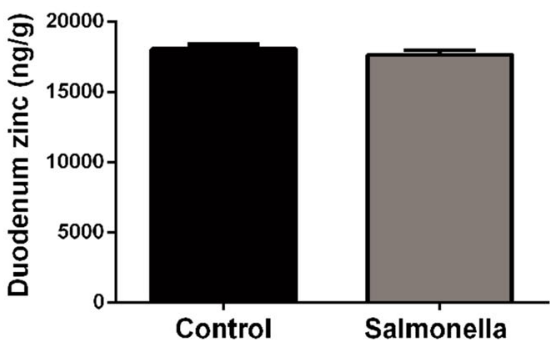

7 d post infection

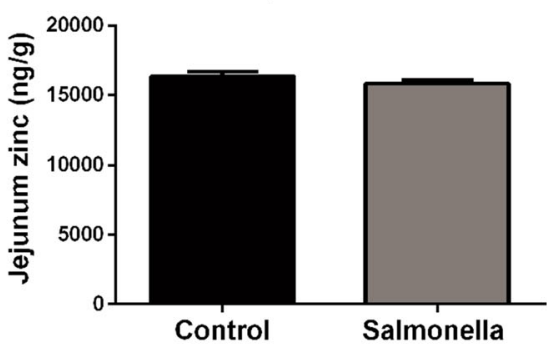

$7 \mathrm{~d}$ post infection

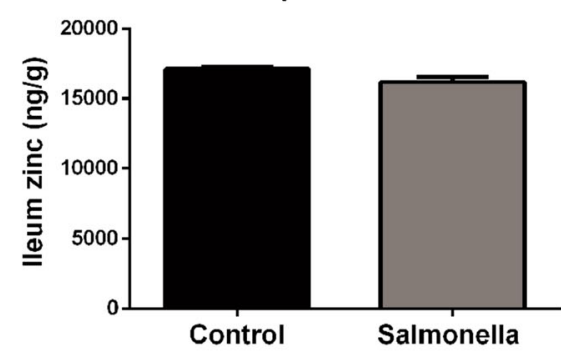

$7 \mathrm{~d}$ post infection

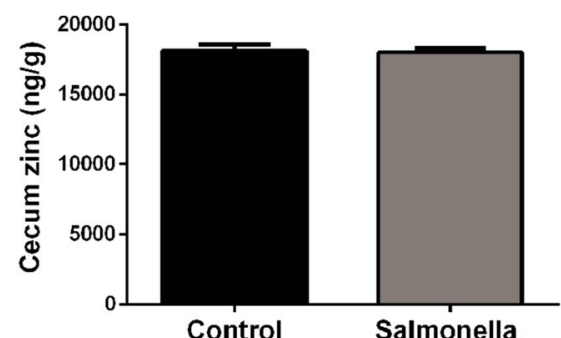

broilers at 1, 3 and 7 days post-challenge were detected by ICP-MS ( $n=$ 8)

was further confirmed in this study. Salmonella challenge substantially decreased the body weight gain of Salmonella-challenged broilers at 3 and 7 days post-challenge. Salmonella challenge impairs the intestinal mucosal barrier and affects the absorption, transfer and utilization of nutrients of the host, which explains this phenomenon [27, 28].

One of the most characteristic features of the acute-phase response to pathogen challenge is a dramatic change in the metabolism of ions, mainly transition metal ions, such as iron, zinc, copper and manganese [25], which are essential for host and pathogen. Consequently, the host has evolved sophisticated sequestration mechanisms to limit pathogen access to these ions [10]. These processes of host-enforced micronutrient restriction are termed "nutritional immunity" [10, 12]. Hypozincaemia induced by Salmonella challenge is believed to belong to the defence arsenal of nutritional immunity [16]. In line with the literature evidence, we revealed that Salmonella-challenged broilers also display hypozincaemia.

Fig. 5 Zinc transporter-mediated zinc redistribution in Salmonella-challenged broilers. Zinc metabolism relative gene mRNA expression in liver (a) and duodenum (b) of broilers at 1 day post-challenge $(n=8)$ 


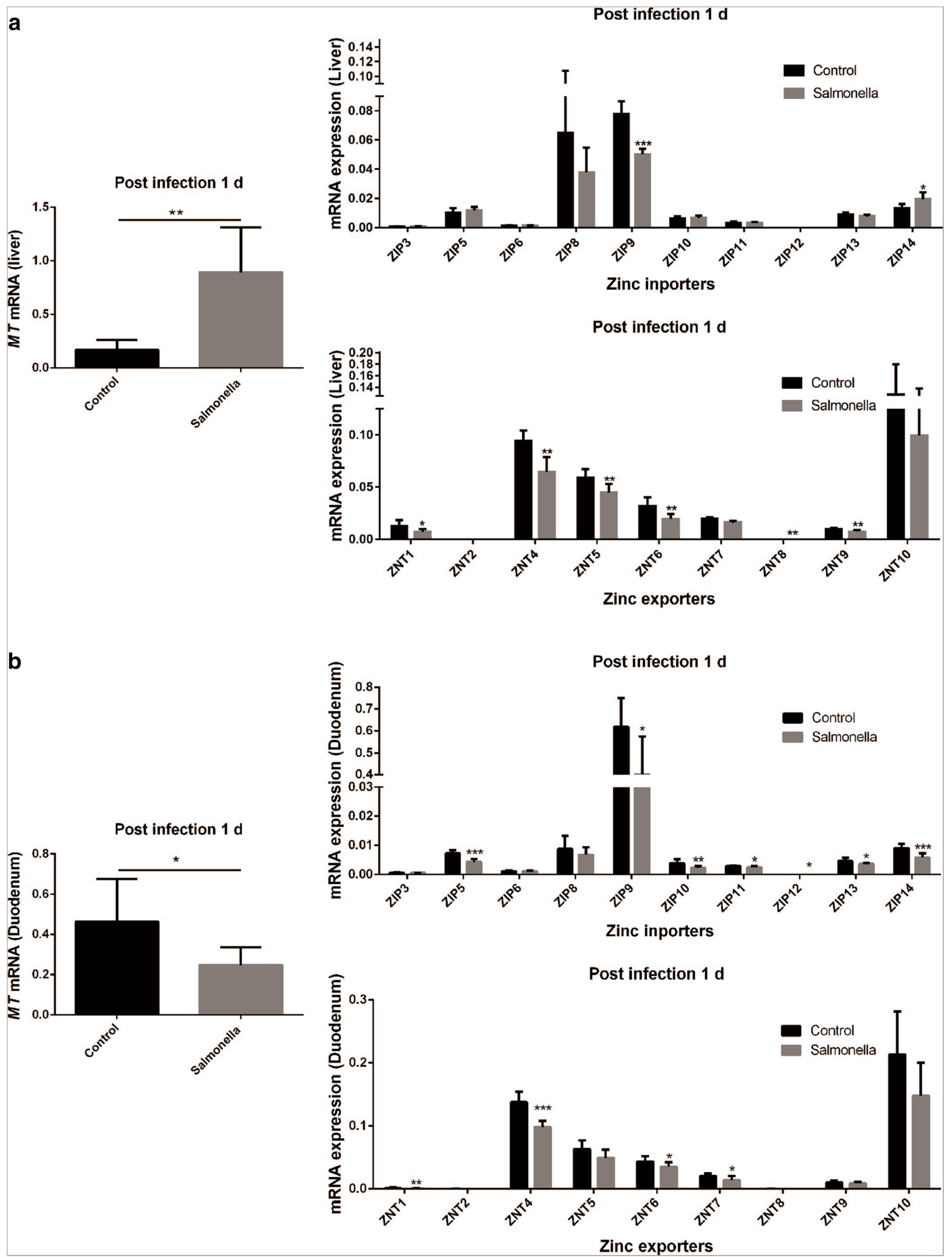


Zinc was redistributed into the liver during the process of acute-phase response to Salmonella challenge, which was also confirmed by the $M T$ mRNA expression in the liver. In addition, we found that the host upregulated zinc importer Zip14 gene expression to redistribute zinc into the liver and downregulated the gene expression levels of zinc exporters $(Z n T 4$, $Z n T 5, Z n T 6, Z n T 8$ and $Z n T 9$ ) to accumulate zinc into the liver. Hypozincaemia is beneficial to reduce zinc availability for Salmonella, which limits Salmonella replication and formation of virulence gene formation $[29,30]$ and redistributes zinc into the liver for hepatic synthesis of acute-phase response proteins $[16,31]$. Thus, it is not surprising that hypozincaemia is an important innate defence strategy.

Accumulating literature evidence shows that immune organs play crucial roles in defence against Salmonella infection [32-34], and mild zinc alteration dramatically affects the function of immune organs [35]. Therefore, we measured the zinc content in the spleen, thymus and bursa of Fabricius. As expected, Salmonella infection causes zinc redistribution into the bursa of Fabricius, a primary central humoral immune organ responsible for establishment and maintenance of the $\mathrm{B}$ cell compartment in avian species $[36,37]$. Zinc accumulation contributes to B cell proliferation and enhances the immune function of the host to against bacterial infection. Furthermore, we also found substantial changes among other ions in the bursa of Fabricius of Salmonella-challenged broilers (data not shown). However, no remarkable changes in zinc were observed in the spleen and thymus.

As zinc is not stored in the body, it has to be ingested daily and its homeostasis needs to be regulated accurately. Salmonella challenge inhibited zinc absorption in the duodenum via downregulation of zinc importer (Zip5, Zip10, Zip11, Zip12, Zip13 and Zip14) mRNA expression, which locate at membranes of cells in mammals and are responsible for zinc absorption from the gut tract. Notably, zinc exporters $Z n T 1$, $Z n T 4, Z n T 6$ and $Z n T 7$ were also downregulated in the duodenum of Salmonella-challenged broilers. These zinc exporters locate at the basement membrane or organelles in the duodenum and contribute to transport zinc from the intestinal epithelium to blood [38-41]. Hence, downregulation of these zinc exporters will significantly lessen the serum zinc concentration, which provides a mechanistic explanation for hypozincaemia.

Overall, we found that the systemic zinc homeostasis of broilers was modulated by Salmonella. Salmonella challenge induced hypozincaemia via limiting zinc absorption in the duodenum and redistributing zinc into the liver and bursa of Fabricius. Zinc transporters play a crucial role in this process, especially ZIP14. These changes in broilers seem to belong to the defence arsenal of the host.

Acknowledgements This work was financially supported by the National Natural Science Foundation of China (Grant No. 31472118), science and technology support project of Sichuan Province (2016NZ0003), and Chelota Group (China) research project (2016LD0001).
Open Access This article is distributed under the terms of the Creative Commons Attribution 4.0 International License (http:// creativecommons.org/licenses/by/4.0/), which permits unrestricted use, distribution, and reproduction in any medium, provided you give appropriate credit to the original author(s) and the source, provide a link to the Creative Commons license, and indicate if changes were made.

\section{References}

1. Zhang B et al (2012) Zinc prevents Salmonella enterica serovar Typhimurium-induced loss of intestinal mucosal barrier function in broiler chickens. Avian Pathol 41:361-367

2. Hohmann EL (2001) Nontyphoidal salmonellosis. Clin Infect Dis 32:263-269

3. Drumo R et al (2015) Salmonella enterica Serovar Typhimurium exploits inflammation to modify swine intestinal microbiota. Front Cell Infect Microbiol 5:106

4. Foley SL et al (2011) Population dynamics of Salmonella enterica serotypes in commercial egg and poultry production. Appl Environ Microbiol 77:4273-4279

5. Liljebjelke KA et al (2005) Vertical and horizontal transmission of salmonella within integrated broiler production system. Foodborne Pathog Dis 2:90-102

6. Fasina YO et al (2008) Intestinal cytokine response of commercial source broiler chicks to Salmonella typhimurium infection. Poult Sci 87:1335-1346

7. Nairz $\mathrm{M}$ et al (2015) Iron regulatory proteins mediate host resistance to Salmonella infection. Cell Host Microbe 18:254-261

8. Fang FC, Weiss G (2014) Iron ERRs with Salmonella. Cell Host Microbe 15:515-516

9. Porcheron G, Garenaux A, Proulx J, Sabri M, Dozois CM (2013) Iron, copper, zinc, and manganese transport and regulation in pathogenic Enterobacteria: correlations between strains, site of infection and the relative importance of the different metal transport systems for virulence. Front Cell Infect Microbiol 3:90

10. Hood MI, Skaar EP (2012) Nutritional immunity: transition metals at the pathogen-host interface. Nat Rev Microbiol 10:525-537

11. Weinberg ED (2009) Iron availability and infection. Biochim Biophys Acta 1790:600-605

12. Barber MF, Elde NC (2014) Nutritional immunity. Escape from bacterial iron piracy through rapid evolution of transferrin. Science 346:1362-1366

13. Lopez CA, Skaar EP (2018) The impact of dietary transition metals on host-bacterial interactions. Cell Host Microbe 23:737-748

14. Kehl-Fie TE, Skaar EP (2010) Nutritional immunity beyond iron: a role for manganese and zinc. Curr Opin Chem Biol 14:218-224

15. Becker KW, Skaar EP (2014) Metal limitation and toxicity at the interface between host and pathogen. FEMS Microbiol Rev 38: $1235-1249$

16. Liuzzi JP et al (2005) Interleukin-6 regulates the zinc transporter Zip14 in liver and contributes to the hypozincemia of the acutephase response. Proc Natl Acad Sci U S A 102:6843-6848

17. Tocco-Bradley R, Kluger MJ (1984) Zinc concentration and survival in rats infected with Salmonella typhimurium. Infect Immun 45:332-338

18. Chua JS, Rofe AM, Coyle P (2006) Dietary zinc supplementation ameliorates LPS-induced teratogenicity in mice. Pediatr Res 59: 355-358

19. Lahiri A, Abraham C (2014) Activation of pattern recognition receptors up-regulates metallothioneins, thereby increasing intracellular accumulation of zinc, autophagy, and bacterial clearance by macrophages. Gastroenterology 147:835-846 
20. Wu A, Tymoszuk P, Haschka D, Heeke S, Dichtl S, Petzer V, Seifert M, Hilbe R, Sopper S, Talasz H, Bumann D, Lass-Flörl C, Theurl I, Zhang K, Weiss G (2017) Salmonella utilizes zinc to subvert antimicrobial host defense of macrophages via modulation of NFkappaB signaling. Infect Immun 85(12)

21. Klasing KC (1984) Effect of inflammatory agents and interleukin 1 on iron and zinc metabolism. Am J Phys 247:R901-R904

22. Pan $\mathrm{S}$ et al (2018) Effect of high dietary manganese on the immune responses of broilers following oral Salmonella typhimurium inoculation. Biol Trace Elem Res 181:347-360

23. Livak KJ, Schmittgen TD (2001) Analysis of relative gene expression data using real-time quantitative PCR and the 2(-Delta Delta $\mathrm{C}(\mathrm{T}))$ method. Methods 25:402-408

24. Sun L et al (2012) Associations between ionomic profile and metabolic abnormalities in human population. PLoS One 7:e38845

25. Skaar EP, Raffatellu M (2015) Metals in infectious diseases and nutritional immunity. Metallomics 7:926-928

26. Vandeplas S et al (2009) Efficiency of a Lactobacillus plantarumxylanase combination on growth performances, microflora populations, and nutrient digestibilities of broilers infected with Salmonella Typhimurium. Poult Sci 88:1643-1654

27. Fasina YO, Hoerr FJ, McKee SR, Conner DE (2010) Influence of Salmonella enterica serovar Typhimurium infection on intestinal goblet cells and villous morphology in broiler chicks. Avian Dis $54: 841-847$

28. van Leeuwen P, Mouwen JM, van der Klis JD, Verstegen MW (2004) Morphology of the small intestinal mucosal surface of broilers in relation to age, diet formulation, small intestinal microflora and performance. Br Poult Sci 45:41-48

29. Ammendola $\mathrm{S}$ et al (2007) High-affinity $\mathrm{Zn} 2+$ uptake system $\mathrm{ZnuABC}$ is required for bacterial zinc homeostasis in intracellular environments and contributes to the virulence of Salmonella enterica. Infect Immun 75:5867-5876

30. Campoy S et al (2002) Role of the high-affinity zinc uptake znuABC system in Salmonella enterica serovar typhimurium virulence. Infect Immun 70:4721-4725

31. Kim S, Watanabe K, Shirahata T, Watarai M (2004) Zinc uptake system (znuA locus) of Brucella abortus is essential for intracellular survival and virulence in mice. J Vet Med Sci 66:1059-1063
32. Brownell JR, Sadler WW, Fanelli MJ (1970) Role of bursa of Fabricius in chicken resistance to Salmonella typhimurium. Avian Dis 14:142-152

33. Ma T et al (2014) Identification of key genes in the response to Salmonella enterica Enteritidis, Salmonella enterica Pullorum, and poly(I:C) in chicken spleen and caecum. Biomed Res Int 2014: 154946

34. Chang $\mathrm{G}$ et al (2015) A mutation in the NLRC5 promoter limits NF-kappaB signaling after Salmonella Enteritidis infection in the spleen of young chickens. Gene 568:117-123

35. King LE, Frentzel JW, Mann JJ, Fraker PJ (2005) Chronic zinc deficiency in mice disrupted T cell lymphopoiesis and erythropoiesis while B cell lymphopoiesis and myelopoiesis were maintained. J Am Coll Nutr 24:494-502

36. Masteller EL, Lee KP, Carlson LM, Thompson CB (1995) Expression of sialyl Lewis(x) and Lewis(x) defines distinct stages of chicken B cell maturation. J Immunol 155:5550-5556

37. Yin Y, Qin T, Yu Q, Yang Q (2014) Bursopentin (BP5) from chicken bursa of fabricius attenuates the immune function of dendritic cells. Amino Acids 46:1763-1774

38. Yu YY, Kirschke CP, Huang L (2007) Immunohistochemical analysis of $\mathrm{ZnT} 1,4,5$, 6, and 7 in the mouse gastrointestinal tract. J Histochem Cytochem 55:223-234

39. Bleck $\mathrm{O}$ et al (2001) Genomic localization, organization and amplification of the human zinc transporter protein gene, ZNT4, and exclusion as a candidate gene in different clinical variants of acrodermatitis enteropathica. Arch Dermatol Res 293:392-396

40. Huang L, Kirschke CP, Gitschier J (2002) Functional characterization of a novel mammalian zinc transporter, ZnT6. J Biol Chem 277:26389-26395

41. Wang X, Wang ZY, Gao HL, Danscher G, Huang L (2006) Localization of $\mathrm{ZnT} 7$ and zinc ions in mouse retinaimmunohistochemistry and selenium autometallography. Brain Res Bull 71:91-96

Publisher's Note Springer Nature remains neutral with regard to jurisdictional claims in published maps and institutional affiliations. 